available for sustaining very disabled people in the place they generally prefer-their own homes. Each district ought to be given the opportunity to plan its strategy in the light of local provision and need and to generate growth in the areas most appropriate to these.

Sadly, the room for manoeuvre has largely disappeared, with health, social services, and housing departments all caught in the straitjacket of government spending and manpower restrictions, and with joint finance mortgaged further and further into the future. This frustration is compounded by the sight of large amounts of money being siphoned off into an area (low dependency residential care) to which few would have given priority, and with an absence of cash limits which seems farcical compared with those having to be met in other parts of the NHS.

Given that the rest home boom will not remain restricted to the affluent south, surely the cost of it spread throughout Britain will be prohibitive? Was a decision really taken that this was judged the area of the care of the elderly in which growth would be most cost effective in the long run? How does that affect the rest of government strategy on the elderly? Experience here and abroad has shown that public subsidy of this sort will improve private sector care only if it is coupled with effective monitoring and enforcement of standards and a proper system for assessing need among prospective clients. When and how will these be introduced? If district planning and participation are to have any meaning should not the responsibility for this audit and the decision on the amount of private care to be employed be handed down, complete with funds, to local social services departments? Whether as planners, NHS waste watchers, taxpayers, or future consumers, we require some answers from the ministers concerned.

Colin GodBer

Consultant Psychogeriatrician,

Moorgreen Hospital,

Southampton $\mathrm{SO} 33 \mathrm{JB}$

${ }^{1}$ Hampshire Registered Rest Homes Association. Leaving the rat race for a life of luxury. Southampton Advertiser 1984 Feb 16:10.

${ }^{2}$ Godber C. The health services 1983; No 50:14.

${ }^{3}$ Director, Hampshire Social Services Department. Services for the elderly: a quality improvement programme. Report to the Social Services Committee 1983;April.

${ }^{4}$ Regulation 9, Supplementary Benefit Requirement. Resource and Single Payment Amendment Regulation. 1983:circular 7/143.

${ }^{5}$ Welsh Office. A good home. Consultative document. 1982.

6 Smith T. Denmark: the elderly living in style. Br Med f 1983;287:1053-5.

7 Smith T. Care of the elderly in the Netherlands. Br Med F 1984;288:127-9.

${ }^{8}$ Ammundsen $\mathrm{E}$. The transition from private to public provision of missing homes in Denmark. Dan Med Bull 1982;29:151-5.

- Godber C. A happier old age in Denmark. Br Med f 1982;284:1729-30.

\section{Drugs and porphyria}

The rapid onset in a patient of alarming symptoms such as severe abdominal pain, paralysis, mania, or coma due to undiagnosed porphyria may alarm the anaesthetist, surgeon, obstetrician, neurologist, or psychiatrist. Such drug induced attacks occur in three types of porphyria: acute intermittent porphyria, variegate porphyria, and hereditary coproporphyria. ${ }^{1-4}$ The second and third of these, distinct biochemically but not clinically, may show diagnostic "porphyric" skin lesions. Acute intermittent porphyria always lacks skin symp- toms and biochemical diagnosis is mandatory. All three conditions have autosomal dominant transmission, and latent disease is frequent. Fortunately none is common, excepting variegate porphyria in white South Africans, for acute attacks have carried a relatively high mortality. Fortunately, too, the "bedside" diagnostic chemical test for the acute attack (for excess urinary porphobilinogen with Ehrlich's reagent) is simple though not without pitfalls. ${ }^{5}$ Why acute systemic reactions to drugs occur in these three porphyrias is still not entirely clear. Some advances have been made, however, in our understanding from studies of experimental porphyrias in animals and tissue culture. 6

What we have for long recognised as the human porphyrias were syndromes of clinicobiochemical abnormalities; but now these can be explained to some extent as the result of deficient activity of one or other specific enzyme of haem biosynthesis together with reactive hyperactivity at the rate limiting enzymatic stage. This leads to accumulation of intermediates behind

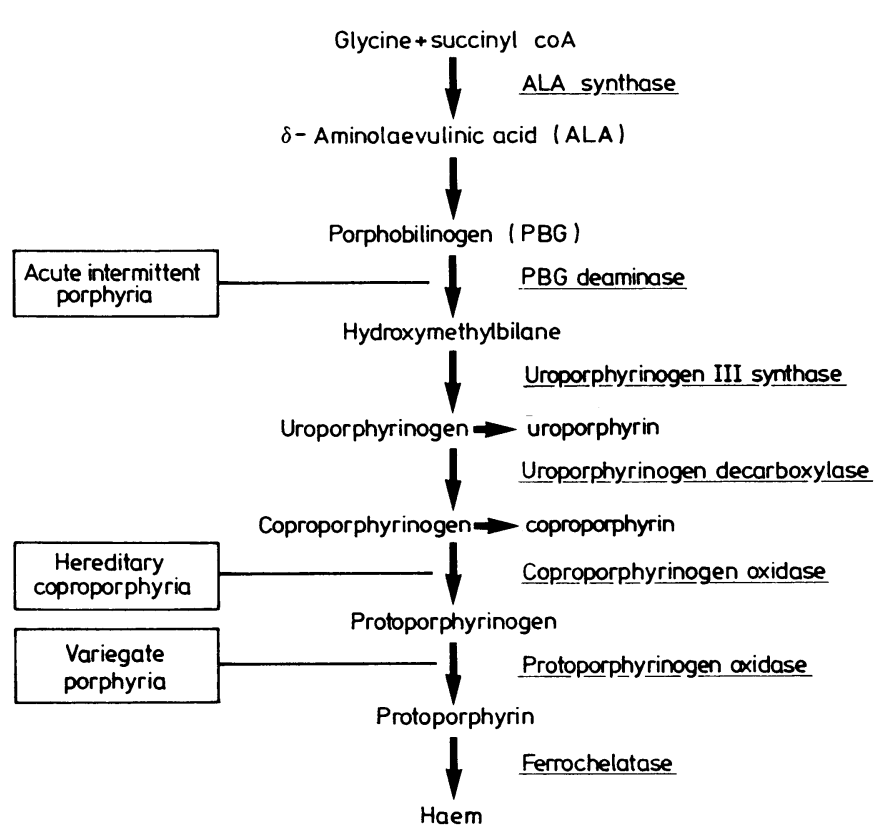

Pathway of haem biosynthesis. Shown in boxes are points at which specific enzymatic deficiency is associated with the three types of porphyria susceptible to drug induced systemic attacks. (Modified from Moore and Disler ${ }^{2}$; with acknowledgment to Oxford University Press.)

the point of block (see figure). Thus in acute intermittent porphyria there is primary deficiency of the enzyme porphobilinogen deaminase. Excess porphobilinogen and $\delta$-aminolaevulinic acid (ALA) are formed; these increase in concentration in both plasma and urine, and their assays are valuable in diagnosis and monitoring. ${ }^{7}$ There is also overactivity (secondary) of the initial enzyme of the pathway ALA synthase-the all important regulator and rate limiting enzyme of haem synthesis. In variegate porphyria the primary deficiency seems to be of protoporphyrinogen oxidase; in hereditary coproporphyria of coproporphyrinogen oxidase. Again there is secondary overactivity of ALA synthase with aggravation of the biochemical defect; it may be this overactivity that precipitates the acute systemic attacks. ${ }^{2}$

Nevertheless, a precise explanation of the attack is not easy. The idea of supposing that all the symptoms are of neurological origin is compelling, and one suggestion is that accumulation of ALA is neurotoxic. ${ }^{1}$ Alternatively, haem deficiency 
in the neurone itself might be the basis of the lesion. Neither hypothesis has much evidence to support it. ${ }^{2}$

Some correlation, however, may be found between the concentration of ALA and the severity of the symptoms. ALA has a chemical structure similar to the neurotransmitter $\gamma$-aminobutyric acid and might possibly be competing for $\gamma$-aminobutyric acid receptor sites. ${ }^{2} 8$ But in experimental systems treatment with ALA has only a modest effect-incompatible with the devastation of neural function seen in patients.

Since deficiency of porphobilinogen deaminase is the primary lesion in acute intermittent porphyria exacerbation of the condition by drugs might reasonably be expected further to diminish directly the activity of that enzyme. Only one drug, carbamazepine, seems to do this. ${ }^{2}$ Most drugs seem to act by altering the control mechanisms of haem biosynthesis (through negative feedback at transcriptional and translational levels) by depleting a conjectural "regulatory haem pool" arising from degradation of hepatic cytochromes, especially P450, during drug detoxification. Other mechanisms have been proposed, and further work is in progress. ${ }^{6}$

These notions have led to the development of a "logical" treatment for acute systemic porphyric attacks-with haematin. Success has been claimed, but further evaluation is needed, and meanwhile intravenous laevulose probably remains the mainstay of treatment. ${ }^{1}$ The most important measure is prevention: avoidance of drugs dangerous in the three susceptible types of porphyria. Such drugs are diverse in chemistry and pharmacology, and the results of screening are not always easy to relate to the patient; but some have been graded for risk and those which are safe defined. ${ }^{2}$ Those established as dangerous now number over 50 and include barbiturates, sulphonamides, anticonvulsants (hydantoins, succinimides), some tranquillisers (for example, meprobamate), the antidiabetic sulphonylureas, and certain non-steroidal anti-inflammatory agents (for example, phenylbutazone). Safe drugs include chlormethiazole, chlorpheniramine, chlorpromazine, propranolol, aspirin, pethidine, and morphine.

Overproduction of ALA and porphobilinogen by a patient with porphyria always indicates a potential drug hazard. But a distinction must be made between the chemicals and drugs that provoke acute systemic attacks in the three porphyrias mentioned above and agents which merely aggravate or precipitate porphyria but not acute attacks. This is illustrated by porphyria cutanea tarda, where overproduction of ALA and acute systemic attacks do not occur; among the agents which may aggravate or precipitate the condition are oestrogens, ethyl alcohol, iron, and polychlorinated aromatic compounds. Furthermore, patients with porphyria cutanea tarda are susceptible to acute liver disturbance from chloroquine, which is turned to therapeutic advantage when given in a prolonged low dose regimen. ${ }^{9}$ This relatively common type of porphyria has diagnostic "porphyric" skin symptoms, no neurological features, and is associated with accumulation (urinary) of uroporphyrin and depression of uroporphyrinogen decarboxylase. In porphyria cutanea tarda it is quite safe to prescribe barbiturates (sedative or anaesthetic), tranquillisers, antiepileptics, and other drugs contraindicated in acute porphyrias. This also applies to the erythropoietic types of porphyrias.

Such varying drug sensitivity highlights the importance of correct diagnosis. Laboratory methods are paramount and entail quantitative assay of urinary porphobilinogen and ALA for confirmation of the attack of acute porphyria. Porphyrins may also be assayed quantitatively in urine and stool for differential diagnosis of the type of porphyria. Other assaysfor example, of enzyme activity in the haem biosynthetic path- ways-are not essential in acute attacks, but in acute intermittent porphyria these methods may be useful for identifying doubtful or latent disease and in family studies.

I A Magnus

Professor of Photobiology,

Institute of Dermatology,

London E9 6BX

${ }^{1}$ Brodie MJ, Goldberg A. Acute hepatic porphyrias. Clin Haematol 1980; 9:253-72.

2 Moore MR, Disler PB. Drug-induction of the acute porphyrias. Adverse Drug Reactions and Acute Poisoning Reviews 1983;2:149-89.

${ }^{3}$ Doss M, von Tiepermann R, Schneider J, Schmid H. New type of hepatic porphyria with porphobilinogen synthase defect and intermittent acute clinical manifestation. Klin Wochenschr 1979;57:1123-7.

${ }^{4}$ Nordman I, Grandchamp B. Coproporphyria hereditaria. Endocrinologia Clinica y Metabolismo 1983;2:58-66.

${ }^{5}$ Elder GH. The porphyrias: clinical chemistry, diagnosis and methodology. Clin Haematol 1980;9:371-98.

${ }^{6}$ de Matteis F. Las porfirias experimentales como modelos de las porfirias hepaticas humanas. Endocrinología Clinica y Metabolismo 1983;2:67-78.

${ }^{7}$ Moore MR. Laboratory investigation of disturbances of porphyrin metabolism. Association of Clinical Pathologists' Broadsheet 1983;No 109:1-15.

${ }^{8}$ Kramer S. Porphyria variegata. Clin Haematol 1980;9:303-22.

${ }^{9}$ Malina L, Chlumský J. Antimalarika v léčbě pozdni kožni porfyrie. Česk Dermatol 1973;48:381-6.

\section{Can we assess the effects of acupuncture?}

Despite all the recent interest in acupuncture among doctors, scientists, and the public confusion persists about how it works - or indeed if it works at all. ${ }^{1}$ Reviews of the technique have tended to concentrate on the mechanism by which it acts as an analgesic rather than its clinical effect on chronic pain. ${ }^{23}$ Nevertheless, some 20 controlled clinical studies have attempted to evaluate acupuncture, mainly for painful musculoskeletal conditions. These studies divide into three broad categories: acupuncture compared with conventional treatment, ${ }^{4-9}$ acupuncture compared with random insertion of acupuncture needles, ${ }^{10-19}$ and acupuncture compared with a physical placebo. ${ }^{20-23}$ The results give an overall impression that acupuncture has an analgesic effect in about $60 \%$ of patients with chronic pain and that it may be more effective than conventional treatment in some specific conditions such as osteoarthritis of the knee and tennis elbow. ${ }^{6} 9$

These trials have not, however, convinced the sceptics. Most were poorly designed, with small numbers of patients, muddled entry criteria, short follow up, and no clear definition of success or failure. Further studies will be needed to overcome doubts and provide a sound basis for the selection of patients for treatment. But is it possible to design a scientifically sound clinical trial of acupuncture versus conventional treatment?

The answer is that convincing studies are hard to designfor several reasons-but the task is not impossible provided that the problems are recognised. Firstly, acupuncture usually has a sustained analgesic effect, ${ }^{6}{ }^{8}$ but one that is unpredictable; some patients find that pain is relieved for only an hour or two while others (receiving exactly the same treatment) report almost complete relief from pain for as long as one or two years. Secondly, the speed of response varies from an immediate improvement in symptoms to a slowly progressive relief of pain. These two features of acupuncture analgesia make crossover trials virtually impossible, and studies need to be designed on a comparative basis. 